\title{
Gesaghebbende Skrifverklaring in die vroeë kerk
}

\author{
C F A Borchardt
}

Abstract

Authoritative interpretation of Scripture in the early church

In the early church the Lord committed his message to his apostles and this was faithfully propagated by those appointed by the apostles and later by their successors, the bishops. The apostolic preaching, Scripture, the interpretation of Scripture and tradition was seen as the heritage of the church. The Church Fathers maintained that the true interpretation of Scripture was to be found in the church alone. The heretics used verses out of their context and emphasized isolated texts to the exclusion of others. They therefore did not have the skopos ekklesiastikos (Athanasius) or sensus scripturae (Hilary) and in this sense a much quoted text by Augustine and the famous dictum of Vincent of Lerins must be interpreted.

Wanneer ons met 'n leerstellige probleem te doen kry, dan vra ons as goeie Protestante allereers wat sê die Skrif oor die betrokke saak. Ons kan ons moeilik in die posisie indink waarin die Christene van die eerste eeue van die kerk se bestaan hulle bevind het. In hulle tyd was daar talle ander godsdienste en afgode. In daardie wêreld moes hulle die boodskap uitdra van een God wat Hom openbaar het as Vader, Seun en Heilige Gees. Die apostels het aanvanklik die blye boodskap uitgedra en ná hulle was daar steeds predikers wat hierdie heilsboodskap voortgedra het. Spoedig was daar egter meningsverskil oor bepaalde aspekte en selfs die apostels moes die stryd aanknoop met dwaalleraars wat die boodskap verkeerd verstaan en oorgedra het.

Die dwaalleraars was nie noodwendig sommer moedswillige mense nie, maar het meesal gemeen dat hulle die apostoliese getuienis suiwer weergee. Naas die Ou Testament het die kerk eers mondelinge oorlewering en later skriftelike neerslag van die verkondiging gehad en so het gaandeweg die vraag ontstaan na die gesaghebbende verklaring van die Skrif. Die dwaalleraars het hulle ook op die Skrif beroep en al het die kerk hulle as ketters gebrandmerk, wou hulle per slot van rekening niks anders doen as om die Skrif uit te lê nie. Aan hierdie worsteling om die Skrif reg te verklaar en veral die norm om dit reg te doen, wil ons kortliks aandag bestee.

Die Bron van alle openbaring was God. Hy het dit egter toevertrou aan profete en wetgewers en boweal aan die apostels wat ooggetuies was van die lewende geïnkarneerde Woord en wat die boodskap aan die kerk deurgegee het. Hierdie outentieke geloof was te vinde in die kerk se deurlopende tradisie van lering en nog meer konkreet in die Heilige Skrif ${ }^{1}$. Ons het dus te doen met die kwessie van die verhouding van Skrif en tradisie. In die westerse Christendom het ons gewoond daaraan geword om dié twee sake te beskou as onderskeie groothede wat soms direk teenoor mekaar gestaan het. In die oosterse Christendom word die woord "tradisie" meer omvattend opgevat, naamlik "it embraces practically everything that goes to make up Christian life and thought, and is indistinguishable from the abiding witness of the Spirit"2. 
Die woord paradosis word dertien keer in die Nuwe Testament gebruik. Nege keer verwys dit na die rabbynse uitbreiding van die wet, drie keer dui dit Christelike tradisie of tradisies aan en een keer die oorlewering van mense. In sommige tekste van die Nuwe Testament word verwys na Christelike tradisie sonder dat die spesifieke woord "tradisie" gebruik word?3.

By die Apostoliese Vaders en Apologete is daar ook verskillende betekenisse aan die woord paradosis geheg, te wete dit wat aan ons oorgelewer is naamlik die geloof van die Inkarnasie (Polikarpus), die reël (kanona) van ons tradisie, naamlik die voorskrifte van godsvrug en boetedoening (l Clemens) en mondelinge oorlewering (Papias). Justinus gebruik die woord "tradisie" in die verskillende betekenisse van sy tyd, te wete dic godsdienstige tradisies van die Hellenisme, geheime mededelinge van die misterieë (Mitras kultus), tradisies wat deur skrifgeleerdes bygevoeg is by die Joodse wet, die leringe wat die Jode van die profete ontvang het, die onderwysinge van Christus self en die eucharistie wat deur Christus ingestel is en aan die apostels oorgelewer is. Die kategetiese onderrig in die tweede eeu was meer op die lewende tradisie gebaseer as op 'n kanon van die Skrif4.

In hierdie vroeë stadium van die kerk se bestaan was daar nie een bepaalde, vaste term om "tradisie", dit is die gesaghebbende oorlewering van die leer, weer te gee nie. Daar was wel spore van die teorie dat die kerk se bedienaars, kragtens die feit dat die Gees aan hulle gegee is, die wettige bewaarders van die apostoliese lering was 5 . Irenaeus skryf dat die Here aan sy dissipels die krag van die evangelie gegee het en hulle het dit eers gepreek en later in die Skrif oorgelewer ${ }^{6}$. Toe het die situasie egter ontstaan dat 'n hele aantal Gnostiese sektes totaal verskillende weergawes van die Christelike waarheid gegee het terwyl hulle aanspraak gemaak het op dieselfde proses van oorlewering. Die Ofiete voer hulle lering na Jesus toe terug deur Jakobus, die broer van die Here, en Basilides se volgelinge sê dat hulle leringe teruggaan tot Mattias, wat Judas se plek ingeneem het as dissipel. Dus langs verskillende weë voer die sektes hul leringe terug tot op die lewende stem van Jesus?.

Die kritieke vraag daarop is hoe die ware tradisie onderskei kan word van die valse tradisie. 'n Beroep op die Skrif is nie genoeg nie, want ook die Gnostici beroep hulle op die Skrif en met behulp van hulle allegoriese uitleg bewys hulle dat dit hulle leringe staaf. Die Gnostici het hulle verder op geheime tradisies beroep ${ }^{8}$. Irenaeus het daarteenoor gestel dat die leer van die apostels openlik bekend is en vas staan en dat hulle nie een stel waarhede in die geheim geleer het en ' $n$ ander stel in die openbaar nie 9 . Die kerklike tradisie was dus openbaar, vir almal kenbaar en juis daarin lê die betroubaarheid en egtheid. Die apostels het, soos 'n ryk man'n deposito in die bank deponeer, alles wat nodig is vir die waarheid, in die kerk se hande geplaas sodat wie ookal wil, die water van die lewe daar kon skep ${ }^{10}$.

Hoe moet die Skrif geinterpreteer word? Irenaeus wys daarop dat die Skrif as geheel geneem moet word. Die ketters het 'n deel van die apostoliese getuienis uitgesoek en nadat hulle dit by hul eie stelsel aangepas het, die gesag van die een bo die ander verhef. Die Ebioniete beroep hulle op Matteus, Marcion op 'n verminkte Lukas, ander weer net op Markus en die Valentiniane op Johannes ${ }^{11}$. Verder neem hulle tekste uit hulle verband en omdat hulle nie op die konteks van die tekste let nie, kan hulle dit gebruik en ombuig om by hulle eie gedagtes aan te pas ${ }^{12}$. Die Skrif moet geïnterpreteer word in ooreenstemming met die oorspronklike openbaring. Daarom was die korrekte eksegese die voorreg van die kerk ${ }^{13}$. 
Die prediking van die kerk is steeds bestendig, in ooreenstemming met die getuienis van die profete, apostels en al die dissipels terwyl die ketters in hul dwaling rondploeter en heen en weer geslinger word terwyl hulle op verskillende tye verskillend dink oor dieselfde teks ${ }^{14}$. God het sy genadegawes binne die kerk geskenk en daar bring die opvolgers van die apostels die waarheid en word die Skrif op juiste wyse uitgele15.

Die prediking is deur die Here aan die apostels toevertrou en deur hulle opvolgers word die prediking voortgesit tot op ons dag. Die Here het aan sy apostels die mag van die evangelie gegee (potestas evangelii) en deur hulle het ons ook die waarheid leer ken. Dit is die leer van die Seun van God aan wie die Here ook gesê het: "Wie na julle luister, luister na My; wie vir julle verwerp, verwerp My; en wie My verwerp, verwerp Hom wat My gestuur het" (Lk 10:16)16. Aanvanklik het die apostels, vervul met die Gees na die uitstorting op Pinksterdag, gepreek en later het hulle dit skriftelik oorgelewer: Markus het Petrus se prediking skriftelik oorgelewer, Lukas het die evangelie wat Paulus gepredik het, opgeteken en Johannes het self sy evangelie uitgegee ${ }^{17}$. Hierdie tradisie wat met die apostels begin is, is altyd in die kerk bewaar deur middel van die suksessie van biskoppe, dit wil sê biskoppe wat deur die apostels en hulle opvolgers georden is. Irenaeus gebruik die lyste van biskoplike suksessie om die regula fidei wat deur die apostels van Christus self ontvang is volledig te identifiseer met die regula fidei wat in sy eie tyd ontvang is in die apostoliese geskrifte wat deur hierdie biskoppe deurgegee is 18 .

Irenaeus het 'n dubbele beginsel daargestel, naamlik die ordinasie van biskoppe en die prediking van hierdie gesagsdraers. Buite hierdie omgrensde gebied is daar geen waarheid nie. In elke kerk is daar die tradisie wat deur die apostels oorgelewer is ${ }^{19}$. Daar is ook 'n identifikasie van die prediking van die apostels en die Skrif. Die prediking is die wese van die Skrif of die interpretasie van die Skrif en die tradisie is wesenlik niks anders nie as die ware interpretasie van die Skrifte en die apostoliese verkondiging. Die apostoliese verkondiging, die Skrif, die interpretasie en die tradisie stel saam een enkele idee daar ${ }^{20}$. Die tradisie is die nie-geskrewe verkondiging en tegelyk ' $n$ beginsel van verkondiging, die norm van interpretasie van die leer wat aan die biskoppe met die "charisma veritatis" toevertrou is. Dit verteenwoordig die werk van God in die kerk, terwyl dit gevoed word deur die Heilige Gees in die harte van die gelowiges. Die Gnostici en ander ketters kom kronologies ná die apostels en hulle wettige opvolgers en hulle preek ook iets nuuts wat die waarheid verderf. Daar is geen onderskeid tussen die apostoliese verkondiging en die goddelike waarheid nie, oral en altyd het die apostels in ooreenstemming met die volle waarheid gepreek ${ }^{21}$.

Soos Irenaeus het ook Tertullianus gemeen dat die regte interpretasie van die Skrif in die kerk te vinde is. Waar die waarheid van die Christelike leer en geloof duidelik aanwesig is, daar sal ook die waarheid van die Skrifte, uitleg en al die Christelike tradisies wees 22 . Trouens, hy ontsê die ketters die reg om oor die Skrifte te redeneer want dit behoort nie aan hulle nie ${ }^{23}$. Nog skerper stel hy dit wanneer hy skryf dat omdat hulle ketters is, is hulle nie Christene nie en daarom het hulle geen reg op die Christelike Skrifte nie ${ }^{24}$.

Verder het die kerk die apostels van die Here as sy waarborge. Hulle het nie hulle eie gedagtes geleer nie, maar die leer wat bulle van Christus ontvang het, getrou gebring 25 . Die ketters werk heeltemal anders, want elkeen verander dit wat hy oordra volgens sy eie gedagtes, net soos die persoon van wie hy dit ontvang het 
dit op sy beurt volgens sy eie gedagtes verander het ${ }^{26}$. Tertullianus het as reël daargestel dat omdat die Here Jesus Christus apostels gestuur het om te preek daar geen ander predikers aanvaar mag word as dié wat Christus ingestel het nie. Die inhoud van hulle prediking, naamlik wat Christus aan hulle openbaar het, kan deur geen ander instansie gekeur word as daardie kerke wat die apostels gestig het nie. Die lering wat met die apostoliese kerke ooreenstem, moet as waarheid gereken word, as dit wat die kerke van die apostels, die apostels van Christus en Christus van God ontvang het ${ }^{27}$. Waar 'n twispunt opduik, is dit nie 'n geval dat die twee disputante op gelyke voet is nie. Daar moet eers gevra word by wie die geloof berus, aan wie die Skrif behoort, van wie en deur wie en wanneer en aan wie die leer oorgelewer is waardeur hulle Christene geword het ${ }^{28}$.

Die ongeskrewe tradisie word deur Tertullianus beskou as dieselfde as die regula fidei, dit wil sê die kardinale waarhede oor God die Vader, Jesus Christus en die Heilige Gees. Die regula is nie 'n formele geloofsbelydenis nie, maar die inhoud van die geloof, dit wil sê die leerinhoud van die Heilige Skrif wat in die apostoliese gemeente trou bewaar is 29 . Dit val saam met die inhoud van die openbaring. "In the rule of faith we have a key to what the Church thought the Scriptures came to, where it was, so to speak, that their weight fell, what was their drift... The rule of faith interprets and detects the drift or burden or main body of truth, the 'scope', of Scripture" 30 .

Nadat die Gnostiese bedreiging verminder het, vind ons in die derde en vierde eeu 'n groter beroep op die Skrif as by Irenaeus en Tertullianus. Ook Clemens van Aleksandrië meen dat die wyse waarop die ketters die Skrif uitlê, onlogies is. Hulle gebruik nie die hele Skrif nie, maar haal tekste uit hulle konteks aan, verdraai dubbelsinnige uitsprake om by hulle eie verklaringe te pas. Hulle speel met woorde en verdraai die betekenis daarvan en leer dus nooit die geheimenisse van die kerk se kennis nie ${ }^{31}$. Die Bybel, soos deur die kerk geinterpreteer, was ook vir hom die bron van die leer ${ }^{32}$. Ook Origenes het hom telkens op die Skrif beroep as die beslissende norm vir die leer ${ }^{33}$. Origenes praat ook van die kanon van geloof, maar beskou dit as die wyse waarop die kerk die Skrif hanteer het en geïnterpreteer het ${ }^{34}$. Hy en Clemens het gemeen dat hulle naas die openlike tradisie van die kerk ook toegang gehad het tot 'n geheime tradisie van lering. Dit was iets wat bestem was vir die intellektuele elite in die kerk ${ }^{35}$.

In die Ariaanse stryd het sowel Arius en sy medestanders as hulle opponente, die ortodokse biskoppe, hulle almal op die ou tradisies en op die Skrif beroep. Athanasius en Hilarius van Poitiers het uitvoerig op die Ariaanse argumente ingegaan en ons wil vervolgens aan hulle beroep op die Skrif aandag gee.

Athanasius het verskeie redes aangevoer waarom hy die Ariane bestry; hulle het van die waarheid afgewyk, hulle is waansinnig en goddeloos en hulle kettery is die voorloper van die Antichris ${ }^{36}$. Hierdie Ariomaniete (Arius-besetenes) het die geloof van die apostels van hulle afgeskud en slegte nuwighede bedink. Hulle het die woorde van die goddelike Skrifte verlaat ${ }^{37}$. Hierdie kettery het net soos sy vader die duiwel, hom met Bybeltekste vermom. Hulle noem hulleself Christene, maar hulle dwaal want hulle ken nie die Skrifte nie en weet niks van die Christendom en die geloof nie 38 .

Die Ariane volg in hulle blindheid net hulle eie wanopvattings en hoewel hulle hul toevlug neem tot die Skrif, sien hulle nie die sin (betekenis) daarvan in nie. Hulle verhef hulle eie goddeloosheid tot maatstaf en verdraai die woorde in die 
Skrif ${ }^{39}$. Hulle haal tekste aan, maar begryp nie die betekenis daarvan nie en terwyl hulle tekste voorhou saai hulle net dwaalleer ${ }^{40}$. Die duiwel gebruik ook Skrifwoorde om sy gif te saai en onskuldiges te bedrieg 41 .

Almal werk dus met dieselfde Skrif, maar die ketters verklaar dit verkeerd want hulle verstaan dit nie reg nie. In die korrekte Skrifverklaring moet mens let op die tydstip waarop die apostel praat, die persoon oor wie dit handel en die saak waaroor hy skryf. Indien 'n mens hierdie drie punte goed begryp, het jy 'n juiste en gesonde begrip van die geloof. Indien hy een van hierdie punte verkeerd opvat, verval hy egter dadelik in dwaalleer ${ }^{42}$. Daar moet ook gelet word op die verband waarin die woorde gebruik word ${ }^{43}$. Die aard van die woorde is ook belangrik want in die geval van beeldspraak of 'n gelykenis, word die woorde nie in die sin wat voor die hand lê, verklaar nie, maar in ooreenstemming met die ware aard daarvan. In Johannes 16:25 het die Here Jesus self gesê dat Hy in beeldspraak gespreek het ${ }^{44}$.

Athanasius was oortuig van die korrektheid van sy eksegese en verwyt die Ariane dat hulle opvatting verkeerd was en dat dit nie die geloof van die kerk was $n^{4}{ }^{45}$. So beskou Athanasius 'n bepaalde opvatting as die mees kerklike ${ }^{46}$. Hy verwys na die skopus ("general bearing or drift"47) en die karakter van die Heilige Skrif ${ }^{48}$. Hy voel dat sy leer in ooreenstemming met dié van die vaders is ${ }^{49}$. Hy verwyt die Ariane dat indien hulle die kerklike gesigspunt (skopos ekklesiastikos) as anker vir die geloof erken het, hulle geloof nie skipbreuk sou gely het nie ${ }^{50}$. Die skopus van die Skrif is tweeërlei: die Heiland was altyd God en Seun, Woord en uitstraling en Wysheid van die Vader, en Hy het later, om ons ontwil, vlees aangeneem uit die maagd Maria en mens geword ${ }^{51}$. 'n Mens moet vanuit hierdie gesigspunt na die Skrif kyk. Tereg is daarop gewys dat wanneer hy na die skopus van die Skrif verwys, hy hom op die Skrif as geheel beroep in teenstelling met wat uit enkele geïsoleerde tekse verkry kan word 52 .

Hoewel die Skrif genoegsaam is om die waarheid te wete te kom, verwys Athanasius ook na die geskrifte van geseënde leermeesters ${ }^{53}$, en ook na die handelinge van die Niceense vaders ${ }^{54}$ as hulp om die Skrif te verstaan. Hierdie uitsprake moet teen die agtergrond van bogenoemde aanhalings gesien word. Die Skrif is voldoende maar moet geinterpreteer word in die lig van die vaders, of soos gesê is, vanuit die kerklike skopus.

Dit is dus duidelik dat vir Athanasius die Skrif en tradisie onlosmaaklik verbonde is ${ }^{55}$. Op sigself is die Skrif volmaak, maar die kerk ontsluit die sin en bedoeling van die Skrif. In die kerk is met die Skrif tegelykertyd die ware interpretasie gegee. Daarmee word nie bedoel dat die tradisie 'n materiële aanvulling van die Skrif sou wees nie, want Skrif en tradisie vorm nie twee selfstandige beginsels wat mekaar aanvul nie, maar een onverbreeklike geheel ${ }^{56}$.

Hilarius van Poitiers, ook genoem die "Athanasius van die Weste"57, het die Ariane net so fel bestry in woord en daad. Hulle is mense met 'n verdraaide gees wat met die skyn van godsdiens hulle dodelike leerstellinge by eenvoudige hoorders inplant 58 . Dit wat hulle lees, pas hulle by hulle eie uitleg aan in plaas van om gehoorsaam te wees aan wat hulle lees (dum quod legitur sensui potius coaptatur quam lectioni sensus obtemperat $)^{59}$. Die ketters meen dat hulle 'n redelike verklaring vir hulle leerstellings bied omdat hulle dit met Skrifbewyse staaf, maar hulle lei net die onkundiges om die bos 60 .

Dit is dus duidelik dat die ketters ook die Skrif aanvoer as bewys vir hulle leerstellinge en meen dat hulle prediking in ooreenstemming is met die Skrif. 
Hilarius meen egter dat dit nie die geval is nie en noem 'n klomp voorbeelde: Marcellus begryp nie wie die Woord van God is wanneer hy die Skrif lees nie; Photinus is onkundig oor die mens Jesus wanneer hy praat; Sabellius verstaan ook nie die teks "Ek en die Vader is een" (Joh 10:30) korrek nie; Montanus verdedig deur sy waansinnige profetesse 'n ander parakleet; Manicheus en Marcion haat die wet. Hulle praat oor al die Skrifte sonder dat hulle die sin (betekenis) van die Skrif het (omnes Scripturas sine Scripturae sensu loquuntur) en hulle gee voor dat hulle glo sonder dat hulle werklik glo. Dit gaan nie om die lees van die Skrif nie, maar om die verstaan daarvan (Scripturae enim non in legendo sunt, sed in intelligendo) ${ }^{61}$. Elders verklaar Hilarius dat daar baie mense was wat die Skrif in ooreenstemming met hulle eie siening verklaar in plaas van om die ware betekenis daaraan te gee. Kettery is volgens hom in die verstaan of begrip geleë en nie in die Skrif nie en die skuld lê by dic interpretasie daarvan en nie by die woord nie (de intelligentia enim heresis. non de scriptura est; et sensus, non sermo fit crimen $)^{62}$.

Die ketters se uitleg van die Skrif lei tot teenstrydige verklarings. So sou Salomo ons tot die verering van 'n skepsel opgeroep het (Spr 8:22 is deur die Ariane gebruik as bewys dat die Seun 'n skepsel was) terwyl Paulus ons verbied om aan 'n skepsel onderdanig te wees (Rom 1:25) ${ }^{63}$.

Hilarius het ook aandag gegee aan die plek wat die rede inneem in ons verklaring van die Skrif. Hy meen dat die swakke mens nie uit homself kennis van God kan kry nie want sy sintuie wat op die liggaamlike ingestel is, kan geen begrip vorm van die onsigbare nie ${ }^{64}$. Die mens in sy swakheid kan slegs weet dat daar 'n God is, maar die aardse mens kan nie tot die dieper geheimenisse deurdring nie 65 . Hy gebruik die volgende illustrasie: Daar is iets in die son wat mens kan sien as hy hom beperk tot wat hy kan, maar hy verloor dit waartoe hy in staat is as hy strewe na dit waartoe hy nie in staat is nie. Die menslike oog kan 'n sekere hoeveelheid sonlig waarneem as hy indirek daarna kyk. As hy egter wil sien waartoe hy eintlik nie in staat is nie en direk stip in die son vaskyk, verloor hy sy gesigsvermoë. So kan die mens dit oor God begryp waartoe hy in staat is. As hy egter verder gaan as waartoe hy in staat is, verloor hy sy vermoë van dit waartoe hy wel in staat is ${ }^{66}$. Terwyl die menslike vermoëns nie in staat is om die goddelike wyshede te verstaan nie moet die mens dwaas word in sy eie oë om wys te wees voor God, dit wil sê hy moet die armoede van sy eie rede beseffit.

Daar is volgens Hilarius wel 'n weg om die mens uit sy onmag te help, naamlik die gawe van die geloof wat God gee want daardeur verkry ons swak rede die genade van openbaring68. Daar is geen groter besef by die mens as dat God so groot is dat Hy nie begryp kan word nie, maar dat daar wel in Hom geglo kan word 69 . God gee die mens geloof en skenk hom die gawe van die rede en sodoende is hy in staat om God te kan ken deur die heilige boeke wat deur middel van sy diensknegte aan ons gegee is ${ }^{70}$. Aangesien Hilarius God sien as die outeur en bron van sowel die geloof as die rede, is daar geen teenspraak tussen hierdie twee middele van kennis nie. Daar is inderdaad 'n groot harmonie tussen geloof en rede en die geloof verhef die rede eerder as om dit te onderdruk en die rede weer op sy beurt, indien dit reg gebruik word, ondersteun steeds die geloof ${ }^{71}$.

Hoe moet die Skrif dan wel verklaar word? Hoewel sy eksegese beskryf is as bewonderenswaardig ewewigtig 72 , vind ons nie 'n sistematiese hermeneutiek van die Skrif nie. Hy het 'n praktiese doel voor oë gehad, naamlik om die Ariane te weerlê en die Godheid van Christus te beklemtoon. Tog het hy nagedink oor sy 
Skrifuitleg en hoewel sy gedagtes hieroor verspreid in sy werke voorkom, bewys dit sy teologiese skerpsinnigheid 73 .

Hilarius wil dat die eenvoudige betekenis, wat voor die hand lè, in woorde uitgedruk moet word. As daar van die Vader sprake is, moet ons die eienskappe van 'n vader aan Hom toeken, naamlik dat $\mathrm{Hy}$ 'n Seun gehad het. Net so ook met die Seun. In die naam is opgesluit dat hy 'n vader gehad het en dat hy dieselfde natuur as sy vader het. Dieselfde geld die Heilige Gees ${ }^{74}$. So praat die Ariane van Christus as nie-waarlik-God nie. Hilarius wil weet wat dit beteken om van 'n ware God en 'n nie-ware-God te praat. Dit het tog geen sin om te verwys na vuur en nieware-vuur nie. Vuur kan niks anders wees as ware vuur nie en solank as wat dit die eienskappe van vuur besit, is dit waarlik vuur. Sodra dit die eienskappe van vuur verloor, hou dit op om vuur te wees ${ }^{75}$. Die verband waarin uitsprake voorkom, is ook baie belangrik. Om die ware betekenis van 'n uitspraak te bepaal, moet gelet word op die omstandighede waaronder die woorde uitgespreek is, want die woorde is ondergeskik aan die saak en nie die saak aan die woorde nie ${ }^{76}$. Ons merk hier sekere ooreenkomste tussen Athanasius en Hilarius op.

Verder moet een teks nie oorbeklemtoon word ten koste van die volle boodskap van die Skrif nie. Die Ariane beklemtoon die teks in Deuteronomium 6:4 (Een God) soveel dat hulle die moontlikheid van 'n ander God (Christus) uitsluit. As daar wel 'n ander God (Christus) sou wees, dan is daar nie meer een God nie ${ }^{77}$.

Samevattend kan ons sê dat Hilarius meen dat die woorde in hulle betekenis gesien moet word soos wat hulle daar staan. Die teksverband is belangrik. Een teks moet nie oorbeklemtoon word nie, maar die hele Skrif moet in berekening gebring word. Hilarius beklemtoon dat as mens die Skrif met geloof lees, jy dinge opmerk wat vir ander ongemerk verbygaan. Hy gebruik die beeld van iemand wat niks van plantsoorte af weet nie en 'n stuk land met verskillende kosbare plante verbyloop sonder dat hy iets daarvan opmerk. 'n Kundige sal egter baie kan meedeel oor die verskillende plantsoorte. So sal die oningewyde baie woorde in die Skrif as waardeloos verbygaan, terwyl die persoon wat onderlê is in Godskennis en wat die gawe van die geestelike genade ontvang het, alles sal kan beoordeel en gebruik $^{78}$.

Die Ariane het ook daarop aanspraak gemaak dat hulle deur die Heilige Gees verlig is. Mens kan dan vra waarom Hilarius die sensus scripturae het en die Ariane nie? 'n Nog moeiliker vraag is waarom Marcellus van Ancyra dit op 'n bepaalde stadium gehad het en later nie meer nie. Nadat Marcellus lank deur die Westerse biskoppe en selfs Athanasius en Hilarius as ortodoks gehandhaaf is, het hulle hom later tog veroordeel. Wat is die maatstaf waarvolgens iemand 'n teks reg interpreteer en 'n ander in dwaalleer verval?

Hilarius gebruik vyf keer die uitdrukking "katolieke geloof", dertien maal "geloof van die kerk", twintig keer "die evangeliese geloof" en meer as dertig keer "die apostoliese geloof"79. Hy gebruik nie die term regula fidei nie, maar dit is wat hy bedoel wanneer hy die terme fides evangelica, fides apostolica of fides ecclesiastica gebruik.

Vir Hilarius was dit duidelik dat die ketter verkeerd redeneer omdat hy nie die ware geloof het nie. Die ware geloof vind ons in die Skrif, maar slegs die kerk kan die Skrif korrek vertolk. Die kerk preek in teenstelling met die ketters die waarheid van die misterie van die geloof. Soos hy êrens sê: alleen binne die kerk is die woord van die lewe en die prediking en diegene daarbuite kan dit nie begryp 
nie $^{80}$. Met die Heilige Skrif is die ware interpretasie aan die kerk gegee en ons moderne vraag wat sedert die hervorming akuut geword het, naamlik waar die objektiewe houvas skuil om hierdie interpretasie te onderken en te toets, het nie vir hulle bestaan nie. Die geloof het saamgeval met die kerk en kan nie faal nie en faal ook nie in homself nie omdat Christus in alle geval self die bron is wat lewe gee. Dit was die gelukkige tyd toe daar geen distansie bestaan het tussen kerk en geloof, tussen amp en Heilige Gees, tussen kerk en Skrif en tussen Skrif, kerk en geloof nie 81 .

In die lig van bogenoemde wil ek enkele opmerkings maak oor Augustinus en Vincentius van Lerinum. Augustinus het ook gemeen dat moeilik verstaanbare gedeeltes in die Skrif opgehelder moet word deur die regula fidei. Die outoriteit van die kerk waarborg die waarheid daarvan. In die sin moet sy dikwels aangehaalde woorde "ek sou nie die evangelie geglo het as die gesag van die katolieke kerk my nie daartoe beweeg het nie" verstaan word. Die gesag van die evangelie word nie afhanklik gemaak van die kerk nie, maar die kerk geld as die reële, teenwoordige getuie vir die evangelie 82 . Die kerk het 'n praktiese prioriteit. In die middeleeue is die uitspraak deur baie mense verkeerd gebruik asof dit 'n metafisiese outoriteit besit, naamlik dat dit die kerk is wat die Heilige Skrif goedkeur en skep ${ }^{83}$. Skrif en tradisie staan nie teenoor mekaar nie, maar is komplementêre outoriteite.

Vanaf die vierde eeu het skrywers hulle al meer op die vaders en op konsiliebesluite as bewakers en verklaarders van die kerk se tradisie beroep. Alhoewel daar groot eerbied vir die vaders was, is daar nooit gedink dat hulle toegang tot ander waarhede gehad het as wat in die Skrif vervat is nie.

Die resultate van hierdie ontwikkeling is saamgevat deur Vincentius van Lerinum teen die middel van die vyfde eeu. Twee dinge is volgens hom nodig: die gesag van die goddelike wet (Bybel) en die tradisie van die Katolieke Kerk. Die Skrif is genoegsaam en meer as voldoende maar moet deur die kerk geïnterpreteer word, omdat daar so ' $n$ verskeidenheid interpretasies moontlik is. Die consensus van die vaders bied 'n waarborg teen 'n willekeurige verklaring. Die norm vir kerklike en katolieke denke is dit wat orals, altyd en deur almal geglo is (quod ubique, quod semper, quod ab omnibus creditum est $)^{84}$.

\section{NOTAS:}

1 J N D Kelly, Early Christian doctrines, London 51977, 29-30.

2 F F Bruce, Scripture in relation to tradition and reason, in Scripture tradition and reason (Essays in honour of Richard P C Hanson, Edited by $\mathrm{R}$ Bauckham and B Drewery), Edinburgh 1988, 37.

3 R P C Hanson, Tradition in the early Church, London 1962, 10.

4 J Daniélou, Gospel message and Hellenistic culture (A history of Early Christian doctrine before the council of Nicea vol 2, transl by $\mathbf{J}$ A Baker), London 1973, 140-141.

$5 \quad$ Kelly, $a w, 35.1$ Clem 42; Justinus, 1 Apol 42.4. 
6 Irenaeus, Adv haer, III 1.1 (S C 211.20).

7 M Wiles, The patiistic appeal to tradition, Explorations in theology, London $1973,43$.

8 Irenaeus, Adversus haereses, III 2.1 (S C 211.26); Tertullianus, De praescriptione haereticonum, 22.2 (C C 1.203).

9 Irenaeus, Adv haer, III 15.1 (S C 211.278).

10 Irenaeus, $a w$, III 4.1 (S C 211.44).

11 Irenaeus, $a w$, III 11.7 (S C 211.158,160).

12 Irenaeus, $a w$, I 8.1 (S C 264.112); I 9.4 (S C 264.146).

13 E F Osborn, Reason and the rule of faith in the second century AD, The making of orthodoxy (Essays in honour of Henry Chadwick, Edited by Rowan Williams), Cambridge 1989, 51.

14 Irenaeus, $a w$, III 24.1,2 (S C 211.470,474).

$15 A w$, IV 26.5 (S C 100.728).

$16 A$ w, III praef (S C 211.20).

$17 \quad A w$, III 1.1-2 (S C 211.22,24)

18 H A Oberman, "Quo vadis? Tradition from Irenaeus to Humani Generis", Scottish Joumal of Theology 16(1963), 229.

19 Irenaeus, $a w$, III 3.1 (S C 211.30).

20 J N Bakhuizen van den Brink, Tradition und Heilige Schrift am Anfang des dritten Jahrhunderts, Ecclesia II, "s-Gravenhage 1966, 5-6.

21 Bakhuizen van den Brink, $a w, 7-8$.

22 Tertullianus, De praescr haer, 19.3 (C C 1.201).

23 Tertullianus, $a w, 15.2-4$ (C C 1.199).

$24 \quad A w, 27.2-3(\mathrm{C} \mathrm{C} 1.217)$.

$25 \quad A w, 6.4$ (C C 1.191).

$26 A w, 42.7$ (C C 1.222$)$.

$27 \quad A w, 21.1-4(\mathrm{C} \mathrm{C} 1.202-3)$

$28 \quad A w, 19.2$ (C C 1.201).

29 J N Bakhuizen van den Brink, Traditio im theologischen Sinne, Ecclesia II, 
's-Gravenhage 1966, 57.

30 Hanson, $a w, 128,253$.

31 Clemens Alexandrinus, Stromata, VII 16.97.

$32 A w$, VII 16.93

33 Origenes, De principiis, I praef.10 (S C 252.88); I 5.4 (S C 252.182-4); II 5.3 (S C 252.296).

$34 \quad$ Hanson, $a w, 79$.

$35 \quad$ Kelly, $a w, 43$.

36 Athanasius, Oratio contra Arianos, I 1 (P G 26.12-15).

$37 A w$, I 4 (P G 26.20).

$38 \quad A w, I 1(\mathrm{P} \mathrm{G} 26.15)$.

$39 A w, I 52$ (P G 26.121).

$40 \quad A w$, I 53 (P G 26.121).

$41 \quad A w, \mathrm{I} 8$ (P G 26.25).

$42 \quad A w, I 54$ (P G 26.124-5).

$43 \quad A w, I 11$ (P G 26.36).

$44 A w$, II 44 (P G 26.240).

$45 A w, I 38$ (P G 26.89-92).

$46 \quad A w, I 44$ (P G 26.101).

47 T E Pollard, "The exegesis of Scripture and the Arian controversy", Bulletin of the John Rylands Library 41(1958-9), 423.

48 Athanasius, $a w$, III 29 (P G 26.385).

$49 A w$, III 18 (P G 26.360).

$50 \quad A w$, III 58 (P G 26.445).

$51 \quad A w$, III 29 (P G 26.385).

$52 \quad$ Pollard, $a w, 424$.

53 Athanasius, Oratio contra gentes, 1 (P G 25.4).

54 Athanasius, De synodis, 6 (P G 26.689). 
$55 \mathrm{C} \mathrm{J}$ de Vogel, Athanasius Redevoeringen tegen de Arianen, Utrecht en Brussel 1949, XXXI.

56 A van Haarlem, Incarnatie en verlossing bij Athanasius, Wageningen 1961, 108.

$57 \quad$ K Hase, Kirchengeschichte, Leipzig 21836, 137.

$58 \quad$ Hilarius, De Trinitate, VIII 2 (C C 62A.313).

$59 A w$, VII 4 (C C 62.263); cf X 2 ((C C 62A.460).

$60 A w$, IV 7 (C C 62.106).

61 Hilarius, Ad Constantium Augustum, II 9 (P L 10.569-570).

62 Hilarius, De Trinitate, II 3 (C C 62.39).

$63 A w$, XII 3 (C C 62A.581).

$64 A w$, IV 14 (C C 62.115).

65 Hilarius, Tractabus in Psalmos, CXXIX 1 (P L 9.718).

66 Hilarius, De Trinitate, X 53 (C C 62A.507-508).

$67 A w, V 1(\mathrm{C} \mathrm{C} 62.150)$.

$68 A w, \mathrm{XI} 23$ (C C 62A.553).

$69 A w$, I 8 (C C 62.8).

$70 A w$, VI 19 (C C 62.218).

$71 \mathrm{~J}$ E Emmenegger, The functions of faith and reason in the theology of Saint Hilary of Poitiers, Washington 1947, 229.

72 C Kannengieser, L'exégẽse d'Hilaire, Hilaire et son temps, Paris 1969, 140.

73 G M Newlands, Hilary of Poitiers: a study in theological method, Bern/Frankfurt am Main 1978, 109 n 28.

74 Hilarius, De Trinitate, II 3 (C C 62.39).

$75 A w, \mathrm{~V} 14$ (C C 62.163).

$76 A w$, IV 14 (C C 62.115-116).

$77 \quad A w, V 1(\mathrm{C} \mathrm{C} 62.152)$.

78 Hilarius, Tractabus in Psalmos, CXXXIV 1 (P L 9.753). 
79 P Smulders, La doctrine trinitaire de S Hilaire de Poitiers, Romae 1944, 107 n 1.

80 Hilarius, In Mattheum, 13.1 (S C 254.296).

81 J N Bakhuizen van den Brink, Traditie, Ecclesia II, 's-Gravenhage 1966, 29.

82 J N Bakhuizen van den Brink, Handboek der Kerkgeschiedenis, Den Haag 41965, deel 1259.

83 Oberman, $a w, 235-236$.

84 Kelly, $a w, 50$; Oberman, $a w, 236-237$. 